\title{
Beautiful death: point of view
}

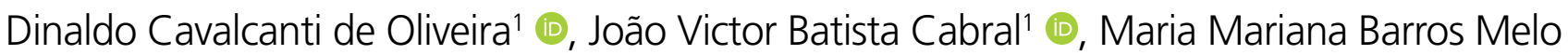 \\ da Silveira' (10, Carolina Gomes Cavalcanti de Oliveira² (10, Dário Celestino Sobral Filho ${ }^{3}$
}

\section{INTRODUCTION}

Sparta is known as a city whose people were specialized in war, and indeed it was ${ }^{1}$. When people from all over the world think of Sparta, they think of a powerful army and men trained for combat, violence, conquest, victory, defeat, etc. However, one day, that image was supplanted by the value of other cities. I invite you to reflect on whether that city was associated only with war and brutality.

There is a certain historical episode ${ }^{2}$, adapted for film, in which 300 Spartan warriors were strategically positioned in one place to "delay" an extremely powerful army so that some Spartan objectives could be achieved. In this description, I do not intend to go into all the details of this battle, but I invite you to put yourself in the place of those 300 warriors.

Certainly, that strategic decision was not instantaneous, some time elapsed between when the decision was made and when the warriors reached the determined place. Let us imagine something: when it was announced that 300 warriors were needed for such a mission, surely there was a group of prequalified warriors, who spent a lifetime preparing for such a task.

However, when the mission arrived, expectation turned to reality. We can wonder if, at some point, those warriors wanted to give up; it would be a great battle, but the probability of defeat and death was immense, practically $100 \%$.

How, then, did the chosen warriors prepare to march toward the place to face the enemy army? Did they feel fear? Fear of death itself? Who would be with the wives and children of those warriors? Who would support their family? Should we take part in a battle that is already lost? Did those Spartans have thought about these and other questions?

Some Greek warriors wished to have a noble death (kalos thanein $)^{3}$, which was only possible when facing an enemy during a challenging journey that must be accepted consciously with courage and morals.
They were fully aware of the concept of a beautiful death (kalos thanatos) ${ }^{3}$, and when facing certain death without any possibility of living, one should seek the kalos thanatos. Therefore, death is an act of heroic confrontation, worthy of the crown of life.

The search for a glorious death (euklees thanatos) ${ }^{3}$ was something that existed in some Greek cultures since antiquity, and immortal fame (kleos aphthiton) was also an object of desire.

Such cultures put value in ideals of virtue, dignity, a desire to do good, a code of morality, a sense that there was something beyond death (an afterlife), and a heroic inscription. Life is lived within the precepts of virtue, following the moral values people believe, and practicing good. I understand that there is something beyond death, and that we should live our lives in a manner that would leave a legacy for the rest of humanity ${ }^{4,5}$.

Based on the concept of kalos thanatos, we can understand that, while we are alive, we should immerse ourselves in cultural, economic, and social activities, leading us to take positive actions that impact our lives and the lives of others, and understand that has meaning. We should transform our lives into a journey in which death is a specific point, but not the end by itself.

Thus, if we believe that those 300 Greek warriors developed their faith and took actions based on the concepts described above, we can understand that in no way did they see going into battle against the mighty enemy army as an act of giving up or fear it, even if death were certain.

We must believe that those 300 noble men lived their lives continually preparing for battle, for war. They gave their best during training; sought to evolve, grow, and learn from their mistakes; understood that their role was not that of a lone warrior fighting, but being part of an army in which each warrior had a specific function; and accepted that the final objective, i.e., victory, would be the product of collective efforts.

\footnotetext{
'Univervidade Federal de Pernambuco, Programa de Pós-Graduação em Inovação Terapêutica - Recife (PE), Brazil.

${ }^{2}$ Faculdade Maurício de Nassau - Recife (PE), Brazil.

${ }_{3}^{3}$ Univervidade Federal de Pernambuco, Programa de Pós-Graduação em Ciências da Saúde - Recife (PE), Brazil.

*Corresponding author: jvbcabral@gmail.com

Conflicts of interest: the authors declare there is no conflicts of interest. Funding: none.

Received on November 20, 2020. Accepted on December 13, 2020.
} 
The Spartans understood that there was an enemy that could not be defeated, i.e., death. However, they did not believe death was the end, but rather the beginning of a new stage. To be valorous, this new stage should follow a life lived with dignity and moral values, leaving a legacy for those who continue to live $^{6}$. Those 300 men left their legacy.

Aging is a normal human process. Depending on the country of residence, a person can be considered "older" when they are 60 or 65 years old. Not all older people are the same, and we must understand that humans have a biological and functional age ${ }^{7,8}$.

Health professionals are in a battle. We try to promote health, avoid diseases, treat or cure them, or offer some comfort. However, we all know that death is certain, sooner or later.

Therefore, we should try to be prepared for death and help our patients to be prepared as well. In this sense, there are many opportunities to be explored by human beings, whether health professionals or not.

A good death comprises a set of characteristics for facing death, including seeking to improve the quality of the dying process in the remaining period of life?

A good death may be related to being cared for with love, affection, and dedication; avoiding physical, psychic or emotional suffering; being surrounded by those you love and were loved by; avoiding conflict with your team of health professionals; having some control over your death; reducing or eliminating pain; and having your preferences respected. It also includes resolving unfinished businesses, eliminating false expectations, accessing specialists, receiving palliative care (PC), and so on ${ }^{9}$.

When a person dies, they disappear from the society; this rupture can lead to very damaging consequences. To minimize them and to resume the path of life, those who remain alive ritualize the situation with funerals, burials, sharing of goods, tributes, mourning, etc. In this way, society remains alive and strengthened".

According to the World Health Organization (WHO), PC comprises assistance provided by a multidisciplinary team with the objective of improving the quality of life of patients and their families in the face of a life-threatening disease. This is achieved through the prevention and relief of suffering, early identification of the illness, impeccable evaluation and treatment of pain, and other physical, social, psychological, and spiritual complaints ${ }^{10}$. The WHO showed that only $14 \%$ of patients worldwide needing $\mathrm{PC}$ receive this type of attention ${ }^{11}$.

Unfortunately, PC training is not often included in the educational curriculum of health professionals. Moreover, the availability of drugs for pain-the most basic topic when talking about minimizing patient suffering-is unfortunately inadequate in most parts of the world ${ }^{12}$.

It is necessary to be prepared for death, both as a person and as a society. From the perspective of health professionals, undergraduate curricula need to be adjusted for this purpose. Moreover, there is also a need for continuous learning after joining the workforce. Health professionals should help prepare their patients for a good death, starting from when the patient has a serious illness with the probability of death or even earlier.

As human beings, we must be prepared to face the certainty of death, building a happy life through physical, economic, financial, religious planning, etc. We must live the present but understand that the past existed; we must learn from our mistakes and successes, so that we can live better lives. To ensure happiness in the future, we must understand that we can achieve the things we imagine, desire, and hope for thorough planning and, if necessary, adapt to possible changes, but sometimes we won't be having what we wanted, so we must begin again having a new dream!

Human beings should accept death as a fact and part of life, and life should be happy, joyful, and pleasant based on moral and cultural precepts.

When a disease is diagnosed by a health professional, it should be understood that many of them will lead to death over the years and that aging increases the chance of death.

Therefore, healthcare professionals should accept the journey of facing death with their patients. However, this should not be a journey of dread, anguish, suffering, and the like. In this context, several actions by healthcare professionals (such as type of communication with the patient and family, attention, showing concern and love, and honesty) have the potential to have a positive impact on people. In addition, spirituality, regardless of religious belief, has the potential benefit. I invite health professionals to dream about these possibilities with us and to make a positive difference in people's lives!

The greatest battle on this journey "takes place in the mind." Obviously, there are other confrontations in the human body that are sometimes painful; however, the battle of thoughts, beliefs, convictions, values, and traditions is fundamental. Therefore, regardless of whether there is an adverse situation or not, the person, patient, or human being should be at peace, comforted, joyful, smiling, feeling good, and supported. Have we never seen a patient having a serious illness with a short-life expectancy but well, happy, and laughing?

Health professionals should not just provide technical assistance or limit themselves to offering patients the best scientific assistance possible, they should instead be part of a multidisciplinary team working toward the greatest goal, i.e., to do good for the patient.

Each team member must fully exercise his/her abilities in the physical and psychological aspects as well. It is necessary to have professionals thriving to have mastery over all areas of human health, leading to a multidisciplinary team offering physical and psychic care to promote health and care for the 
patient. Individuality must be left at the door, and health professionals must understand that the collective is what makes a difference in our profession.

We must work as a team in which communication should be effective, actions are undertaken together and aim at a common goal, each member supports the others, moral and ethical values are prioritized, knowledge and experiences are shared, the management is respectful and works in harmony with the rest of the team, and so on.

The time has come for a revolution! It is time for us to reinvent healthcare, promote health from pregnancy and throughout life, understand that health is a continuum, and recognize that death is certain but the journey of life can be pleasant and happy. At this time, we should not only be health professionals but also be in health teams in which potential and ability of each individual emerges and the whole is used for the benefit of the people.

In this way, death will not be seen as something to be feared or as a desperate, distressing event, because life will have meaning: a legacy will be left, there will be an understanding of the natural history of human life and death, and with this, death can be understood as another life event.

In order to facilitate a good death to our patients, we need to work together with them, their families, their friends, and the society to understand the cycle of life, accepting death as an event in this cycle. We need to develop knowledge of this journey through beliefs, cultural values, traditions, etc., and as health professionals, we cannot fall behind. We should share our vision of the life cycle with our patients and with society, but also seek broader knowledge of this process and of the various historical strategies of facing death. Death should not be an unprepared event in people's lives.

Sometimes, death is the solution: freedom. For some people in hospital rooms, in bed, lying down without contact with the outside world, death can be liberating. Let us share with you one case: a patient well-known to Dinaldo Cavalcanti de Oliveira (DCO) was with tracheostomy (cervical region) in the room. The patient's monitor showed a $60 \mathrm{bpm}$, and beside him was a caregiver. The window was closed, and the room was almost absolutely silent. DCO entered the room and asked the caregiver to leave. DCO was now next to the bed, staring into his eyes that seemed to want to tell something; however, no words came out of his mouth, which insistently remained closed and immovable. In that moment, the childhood flashed through DCO's mind: the jokes and smiles they had together, their trips, family celebrations, his happy way of speaking, his children who were all working professionals, and his frequent family reunions to celebrate happy occasions (the last one two months ago to celebrate his 99th birthday). Now, the man who smiled and played with everyone at his party was lying in that bed immovable. Nobody anticipated the overwhelming stroke that put him in this situation, although they always knew that one day something would happen to end his life. Two months alive in a hospital room; alive but lifeless. The tears came down from eyes, DCO could not help calling out to him “...let's travel, let's go to the beach... I miss you". At that moment, looking into his eyes, DCO saw tears flowing down. DCO was static for about one minute, surprised by the sound of the monitor warning that his heart rate was below $60 \mathrm{bpm}$. It was decreasing together with the blood pressure; soon after, there was a flat line on the monitor. He was no longer in that room; the journey of his battle had been crowned with memorable victories, unforgettable ones that left marks in the lives of many; marks that are impossible to forget or erase. He lived for two months on a bed, inert, passive, alive without being alive, and now he was no longer there; he had passed on to a glorious phase: death. Death, where is your victory? His life became immortal because those who lived with him are carrying on his legacy, and he continues his journey even though he is no longer in this world!

\section{CONCLUSIONS}

Healthcare professionals should accept the journey of facing death with their patients. However, this should not be a journey of dread, anguish, suffering, and so on. In this context, several actions by healthcare professionals have the potential to make a positive impact on people and the patients alike.

The time has come for a revolution! It is time for us to reinvent healthcare, promote health starting from pregnancy and throughout life, understand that health is a continuum, and recognize that death is certain but the journey of life can be pleasant and happy. At this time, we should not only be health professionals but also be in health teams in which the potential and ability of each individual emerges and the whole is used for the benefit of people.

\section{AUTHORS' CONTRIBUTIONS}

DCO: Conceptualization, Data curation, Formal analysis, Funding acquisition, Investigation, Methodology, Project administration, Resources, Software, Supervision, Validation, Visualization, Writing - original draft, Writing - review \& editing. JVBC: Data curation, Formal analysis, Investigation, Methodology, Software, Writing - original draft, Writing - review \& editing. MMBMS: Data curation, Formal analysis, Investigation, Methodology, Software, Writing - original draft, Writing - review \& editing. CGCO: Data curation, Formal analysis, Investigation, Methodology, Software, Writing - original draft, Writing - review \& editing. DCSF: Data curation, Formal analysis, Funding acquisition, Investigation, Methodology, Resources, Software, Supervision, Supervision, Validation, Visualization, Writing - original draft, Writing - review \& editing. 


\section{REFERENCES}

1. History.com. Sparta. History [cited on 2020 Jun 06]. Available from: https://www.history.com/topics/ancient-history/sparta.

2. Lohnes K, Sommerville D. Battle of Thermopylae. Greek history [480 BC]. [cited on 2020 Jun 06]. Available from: https://www. britannica.com/event/Battle-of-Thermopylae-Greek-history-480-BC.

3. Beautiful death-Kalos Thanatos. [cited on 2020 Jun 06]. Available from: https://erenow.net/biographies/helen-of-troy-the-storybehind-the-most-beautiful-woman-in-the-world/38.php.

4. History.com. Judaism. History [cited on 2020 Jun 06]. Available from: https://www.history.com/topics/religion/judaism.

5. Egyptians. BBC.com [cited on 2020 Jun 06]. Available from: http://www.bbc.co.uk/history/ancient/egyptians/.

6. Sparta religion. HSC Ancient History [cited on 2020 Jun 06]. Available from: https://sghsancienthistory.wordpress.com/ sparta-2/spartan-religion/

7. Old age. Britannica [cited on 2020 Jun 06]. Available from: https://www.britannica.com/science/old-age
8. Anton SD, Woods AJ, Ashizawa T, Barb D, Buford TW, Carter CS, et al. Successful aging: advancing the science of physical independence in older adults. Ageing Res Rev. 2015;24(Pt B):304-27. https://doi.org/10.1016/j.arr.2015.09.005

9. Floriani CA. Fim da vida, o idoso e a construção da boa morte. In: Freitas EV, Py L, editors Tratado de geriatria e gerontologia. Rio de Janeiro: Guanabara Koogan; 2015. p. 3043-68.

10. Kohler LB, Cerchiaro ACB, Levites MR. Cuidados paliativos ambulatoriais e qualidade de vida em pacientes oncológicos. Diagn Tratamento. 2016;21(3):101-5.

11. Kelley AS, Morrison RS. Palliative care for the seriously III. N Engl J Med. 2015;373(8):747-55. https://doi.org/10.1056/ NEJMra1404684

12. Baxter S, Beckwith SK, Clark D, Cleary J, Falzon D, Glaziou P, et.al. Global atlas of palliative care at the end of life. World Health Organization; 2014 [cited on 2020 Jun 06]. Available from: https://www.who.int/nmh/Global_Atlas_of_Palliative_ Care.pdf. 